\title{
BMJ
}

\section{Determinants of disparities between perceived and physiological risk of falling among elderly people: cohort study}

\author{
Kim Delbaere, postdoctoral researcher, ${ }^{1,2,3}$ Jacqueline C T Close, associate professor, ${ }^{1,4}$ Henry Brodaty, \\ professor, ${ }^{5,6}$ Perminder Sachdev, professor, ${ }^{5,7}$ Stephen R Lord, professor ${ }^{1}$
}

$\overline{1}$ Falls and Balance Research Group, Neuroscience Research Australia, University of New South Wales, Randwick, NSW 2031, Sydney, Australia

${ }^{2}$ Department of ExperimentalClinical and Health Psychology, Faculty of Psychology and

Educational Sciences, Ghent University, Belgium

${ }^{3}$ Department of Rehabilitation Sciences and Physiotherapy, Faculty of Medicine and Health Sciences, Ghent University, Belgium

${ }^{4}$ Prince of Wales Clinical School, University of New South Wales, Randwick, Sydney, Australia

${ }^{5}$ School of Psychiatry, University of New South Wales, Prince of Wales Hospital, Randwick,

Sydney, Australia

${ }^{6}$ Dementia Collaborative Research Centre, University of New South Wales, Sydney, Australia.

${ }^{7}$ Neuropsychiatric Institute, Prince of Wales Hospital, Randwick, Sydney, Australia

Correspondence to: S R Lord s.lord@neura.edu.au

Cite this as: BMJ 2010;341:C4165 doi:10.1136/bmj.

\section{ABSTRACT}

Objectives To gain an understanding of elderly people's fear of falling by exploring the prevalence and determinants of perceived and physiological fall risk and to understand the role of disparities in perceived and physiological risk in the cause of falls.

Design Prospective cohort study.

Setting Community sample drawn from eastern Sydney, Australia.

Participants 500 men and women aged 70-90 years.

Main outcome measures Baseline assessment of medical, physiological, and neuropsychological measures, with physiological fall risk estimated with the physiological profile assessment, and perceived fall risk estimated with the falls efficacy scale international. Participants were followed up monthly for falls over one year.

Results Multivariate logistic regression analyses showed that perceived and physiological fall risk were both independent predictors of future falls. Classification tree analysis was used to split the sample into four groups (vigorous, anxious, stoic, and aware) based on the disparity between physiological and perceived risk of falling. Perceived fall risk was congruent with physiological fall risk in the vigorous (144 (29\%)) and aware (202 (40\%)) groups. The anxious group (54 (11\%)) had a low physiological risk but high perceived fall risk, which was related to depressive symptoms $(P=0.029)$, neurotic personality traits $(P=0.026)$, and decreased executive functioning $(P=0.010)$. The stoic group (100 $(20 \%))$ had a high physiological risk but low perceived fall risk, which was protective for falling and mediated through a positive outlook on life $(P=0.001)$ and maintained physical activity and community participation $(P=0.048)$.

Conclusion Many elderly people underestimated or overestimated their risk of falling. Such disparities between perceived and physiological fall risk were primarily associated with psychological measures and strongly influenced the probability of falling. Measures of both physiological and perceived fall risk should be included in fall risk assessments to allow tailoring of interventions for preventing falls in elderly people.

\section{INTRODUCTION}

Fear of falling in elderly people has been recognised as an important psychological factor associated with falls. Much research has been undertaken to determine how fear of falling affects the lives of elderly people and how it may play a role in the transition to physical frailty and the incidence of falls. Both falls and fear of falls can substantially reduce quality of life and independence and so contribute to the placement of an elderly person into institutional care. ${ }^{1}$ However, the complex nature of psychological risk factors for falling and the limited background information on this phenomenon hamper its inclusion in falls prevention programmes.

Fear of falling has been associated with objectively assessed measures of balance, ${ }^{2}$ gait, ${ }^{3}$ and falls. ${ }^{4-6}$ This could indicate that people are accurate at rating their fall risk and that fear of falling simply reflects a rational appraisal of reduced functional abilities and consequent increased risk of falling. Alternatively fear may be irrational, excessive, or phobic - a construct reflecting the original phobic condition that Bhala et al described in 1982. ${ }^{7}$ Excessive fear of falling can lead to needless restriction in participation in physical and social activities, ${ }^{8}$ resulting in physical deconditioning, ${ }^{45910}$ poor quality of life, ${ }^{48-10}$ social isolation, depression, and psychological distress. ${ }^{11-13}$ From this perspective, fear of falling would be considered maladaptive, and strategies aimed at reducing fear of falling should be implemented. ${ }^{14}$ However, such approaches could be harmful and may even increase the risk of falls if it makes elderly people overly confident. Elderly people with inappropriately low levels of fear of falling might take undue risks beyond their physical ability to cope. It might therefore be important for intervention programmes to help elderly people develop a realistic appraisal of fall risk or improve physical functioning in concert with addressing fear, rather than just reduce fear of falling.

The problem of irrational fear, either too much or too little, has been largely neglected. The primary aim of this study was to increase our understanding of fear of falling by exploring the existence of irrational fear in a large representative sample of elderly people. 
By categorising people in relation to their physiological fall risk and their perceived fall risk, we were able to determine the prevalence of irrational fear of falling. By measuring a diverse range of sociodemographic, cognitive, psychological, and physical factors, we were able to elucidate why elderly people have divergent perceived and physiological fall risks and the impact of such disparities on the risk of falls.

\section{METHODS}

\section{Participants}

A total of 500 people aged 70-90 years participated in the prospective cohort study with a one year follow-up for falls. They were randomly recruited from a cohort of 1037 men and women living in the community in eastern Sydney and participating in the first stage of the Sydney Memory and Ageing Study (January 2006 to October 2007). ${ }^{15}$ Participants in this study were recruited randomly through the electoral roll, for which registration is compulsory for Australian citizens. Potential participants were excluded from the Sydney Memory and Ageing Study if they had a previous diagnosis of dementia or developmental disability, psychotic symptoms, Parkinson's disease, multiple sclerosis, motor neurone disease or central nervous system inflammation, or if they had medical or psychological conditions that might prevent them from completing assessments. Based on data from previous population studies, ${ }^{251617}$ we estimated that a sample size of 300 would allow for a minimum of 10 outcome cases (fallers) per variable entered into multivariate models and be adequate for determining significant differences between people with divergent perceived and physiological risks of falling. ${ }^{18}$

\section{Measures}

At the start of the study, all participants underwent extensive medical, physiological, and neuropsychological assessment by trained research assistants.

\section{Medical assessment}

A complete medical history was recorded during a face-to-face interview, including the presence of medical conditions, medication use, and history of falls. As a measure of comorbidity, each medical condition was given one point from a list of nine system-related conditions (that is, cardiovascular, respiratory, musculoskeletal, endocrine, urogenital, cancer, neurological, mental health, and eye diseases).

The total number of medications was used as a measure of polypharmacy. Use of centrally acting or psychotropic drugs was investigated in more detail because of their established relation to falls and fear of falling. Such drugs included sedatives, hypnotics, antipsychotics, antidepressants, and anxiolytic agents.

Three scales were used to obtain more detailed information on disability, quality of life, and physical activity. A general disability score across six domains (that is, understanding and communicating, mobility, self care, interpersonal interactions, household and work activities, and participation in society) was obtained using the 12 item World Health Organization disability assessment schedule (WHODAS II). ${ }^{19}$ Quality of life was assessed with the 20 item assessment of quality of life (AQoL II) instrument on six dimensions (independent living, social relationships, mental health, coping, pain, and sensory perception). ${ }^{20}$ Participants' average weekly physical activity over the past three months was assessed with the incidental and planned exercise questionnaire (IPEQ), providing estimates of the frequency and duration of planned exercise and more casual day-to-day activities. ${ }^{21}$

\section{Physiological assessment}

We used the physiological profile assessment (PPA) (Neuroscience Research Australia, Sydney NSW, Australia) to estimate the physiological fall risk. ${ }^{16}$ The PPA contains five validated measures of physiological function: visual contrast sensitivity, assessed with the Melbourne edge test; proprioception, measured with a lower limb-matching task, where errors in degrees are recorded with a protractor inscribed on a vertical clear acrylic sheet placed between the legs; quadriceps strength, measured isometrically in the dominant leg while participants are seated with the hip and knee flexed to $90^{\circ}$; simple reaction time, measured with a light as stimulus and a finger press as response; and postural sway (path length), measured with a sway meter recording displacements of the body at the level of the pelvis while participants stand on a foam rubber mat with eyes open. In our multivariate models, weighted contributions from these five variables provide a score that can predict with $75 \%$ accuracy the risk for people living in the community of multiple falls over the next 12 months. ${ }^{16}$ Higher scores on the PPA are assoicated with a greater risk of falls.

In addition, the coordinated stability test assessed the integration of each of these five basic physiological systems in the maintenance of dynamic balance control. ${ }^{22}$ This dynamic balance task requires people to adjust body position in a steady and coordinated way while placing them at or near the limits of their base of support.

\section{Neuropsychological assessment}

Using the falls efficacy scale international (FES-I), we assessed participants' perceived fall risk by asking about concern about falling across a wide range of activities of daily living (such as cleaning the house, shopping, walking on uneven surfaces). FES-I has excellent reliability (Chronbach's $\alpha=0.97$, test-retest $=0.94)$ and validity. ${ }^{23}$ The higher the score, the greater the concern about falling. Additionally, we evaluated several neuropsychological constructs that have been linked with falling or fear of falling-that is, depression, ${ }^{1324}$ anxiety, ${ }^{13}$ neuroticism, ${ }^{25}$ and attention and executive function. ${ }^{26}$ Symptoms of depression were assessed with the 15 item geriatric depression scale (GDS), a validated measure of mood specifically designed for use with elderly people. ${ }^{27}$ Symptoms of anxiety in the past month were assessed with the nine item Goldberg anxiety scale. ${ }^{28}$ Neuroticism was 
assessed with one subdomain of the NEO five factor inventory (NEO-FFI, the short version of the revised NEO personality inventory) ${ }^{29}$ and was used to identify people who were prone to experiencing excessive concerns or showing risk-taking behaviour. Cognitive processing performance was tested with the trail making test, with part $\mathrm{A}$ assessing simple attention and part $\mathrm{B}$ assessing complex attention. ${ }^{30}$ The difference between the two parts was calculated to remove the speed element from the test evaluation, leaving an estimate of executive function.

\section{Falls follow-up}

A fall was defined as an unexpected event in which the participants come to rest on the ground, floor, or lower level. ${ }^{31}$ The number of falls in the previous year was recorded at baseline. Falls frequency during the one year follow-up was monitored with monthly falls diaries. ${ }^{31}$ Participants were also asked whether they had had any injuries as a result of the fall. If a participant's diary was not returned within two weeks of the end of each month, the participant was contacted by telephone.

\section{Statistical analyses}

Fallers were defined as people who had at least one injurious fall or at least two non-injurious falls during the 12 month follow-up period. We used this classification to identify falls that were more likely to have a disabling impact on a person's life.

Individual missing items within a questionnaire were substituted by the mean across items for the falls efficacy scale international, geriatric depression scale, and Goldberg anxiety scale; by the population mean for the measures related to the physiological profile assessment; and by using "missing value analyses" to calculate missing items within questionnaires, using expectation maximisation algorithms based on the other items. Overall, $<5 \%$ of data were missing for any one measure.

For variables with skewed distributions, data were normalised. Logistic regression models were used to calculate univariate and multivariate odds ratios for the associations between physiological fall risk (physiological profile assessment) and perceived fall risk (falls efficacy scale international) with falls in the 494 participants who completed the follow-up.

\begin{tabular}{|c|c|c|c|c|c|c|}
\hline & \multicolumn{3}{|c|}{ Low physiological fall risk* } & \multicolumn{3}{|c|}{ High physiological fall risk* } \\
\hline & $\begin{array}{l}\text { Low perceived risk } \\
\text { ("vigorous") }(n=144)\end{array}$ & $\begin{array}{l}\text { High perceived risk } \dagger \\
\text { ("anxious") }(n=54)\end{array}$ & $\begin{array}{l}\text { P value of } \\
\text { difference }\end{array}$ & $\begin{array}{l}\text { Low perceived risk } \neq \\
\text { ("stoic") }(\mathrm{n}=100)\end{array}$ & $\begin{array}{l}\text { High perceived risk } \\
\text { ("aware") }(\mathrm{n}=202)\end{array}$ & $\begin{array}{l}\text { P value of } \\
\text { difference }\end{array}$ \\
\hline Physiological profile assessment score & $-0.01(0.43)$ & $-0.04(0.43)$ & 0.795 & $1.31(0.60)$ & $1.49(0.70)$ & 0.012 \\
\hline Falls efficacy scale international & $18.70(1.73)$ & $27.46(5.54)$ & $<0.001$ & $17.80(1.13)$ & $26.24(6.70)$ & $<0.001$ \\
\hline Age (years) & 76.27 (3.99) & $77.45(5.04)$ & 0.091 & $77.54(4.31)$ & $79.67(4.51)$ & $<0.001$ \\
\hline No (\%) of female participants & $61(42)$ & $34(63)$ & 0.010 & $54(54)$ & $121(60)$ & 0.186 \\
\hline No of medications per person & $4.77(3.63)$ & $5.35(3.02)$ & 0.284 & $4.87(3.33)$ & $5.95(3.31)$ & 0.010 \\
\hline $\begin{array}{l}\text { No (\%) of participants taking psychotropic } \\
\text { medications }\end{array}$ & $22(15)$ & $9(17)$ & 0.877 & $8(8)$ & $38(18)$ & 0.010 \\
\hline No of medical conditions per person & $2.68(1.35)$ & $3.01(1.54)$ & 0.175 & $2.82(1.46)$ & $3.41(1.63)$ & 0.002 \\
\hline General disability score (WHODAS II) & $15.38(4.14)$ & $20.03(6.18)$ & $<0.001$ & $16.12(4.70)$ & $20.27(6.29)$ & $<0.001$ \\
\hline Quality of life score (AQoL II) & $92.86(4.58)$ & $87.12(8.49)$ & $<0.001$ & $92.86(5.46)$ & $86.62(9.59)$ & $<0.001$ \\
\hline Planned exercise (hours/week) & $2.11(3.46)$ & $2.16(3.86)$ & 0.291 & $2.10(4.91)$ & $1.30(2.19)$ & 0.048 \\
\hline Incidental activity (hours/week) & $32.48(15.93)$ & $32.65(14.23)$ & 0.948 & $32.27(15.50)$ & $30.47(15.78)$ & 0.346 \\
\hline No (\%) of participants with prior falls & $35(24)$ & $19(35)$ & 0.124 & $15(15)$ & $80(40)$ & $<0.001$ \\
\hline No (\%) of participants with injurious falls & $24(17)$ & $18(33)$ & 0.017 & $26(26)$ & $73(36)$ & 0.463 \\
\hline Geriatric depression scale & $1.71(1.69)$ & $2.41(1.60)$ & 0.029 & $1.78(1.80)$ & $2.70(2.17)$ & 0.001 \\
\hline Neuroticism score (NEO-FFI subscale) & $12.64(6.24)$ & $15.00(6.44)$ & 0.026 & $13.83(6.97)$ & $16.44(6.77)$ & 0.001 \\
\hline Goldberg anxiety scale & $0.77(1.36)$ & $1.17(1.77)$ & 0.780 & $0.76(1.38)$ & $1.05(1.70)$ & 0.963 \\
\hline \multicolumn{7}{|l|}{ Cognitive performance (trail making test): } \\
\hline Part A (simple attention, seconds) & $41.31(12.55)$ & $44.73(15.09)$ & 0.153 & $47.81(16.82)$ & $47.95(16.04)$ & 0.866 \\
\hline Part B (complex attention, seconds) & $104.84(44.28)$ & $121.84(55.13)$ & 0.018 & $124.72(55.65)$ & $128.41(56.33)$ & 0.545 \\
\hline Part B-Part A (executive function, seconds) & $63.53(38.55)$ & $77.11(51.69)$ & 0.010 & $76.91(47.33)$ & $80.46(49.91)$ & 0.533 \\
\hline $\begin{array}{l}\text { No (\%) of participants with impaired quadriceps } \\
\text { strength§ }\end{array}$ & $42(29)$ & $24(44)$ & 0.061 & $35(35)$ & $116(57)$ & 0.001 \\
\hline Coordinated stability test (errors) & $9.78(10.45)$ & $13.32(13.01)$ & 0.025 & $15.44(11.47)$ & $19.97(13.22)$ & 0.002 \\
\hline \multicolumn{7}{|c|}{$\begin{array}{l}\text { For the physiological profile assessment, falls efficacy scale international, WHODAS II, Geriatric depression sc } \\
\text { coordinated stability test, high scores indicate impaired performance or poorer status. For the AQoL II, planne } \\
\text { performance or poorer status (see Methods section for details of assessment tests). } \\
\text { *Low and high physiological fall risks were scores of }<0.60 \text { and } \geq 0.60 \text { on physiological profile assessment. } \\
\text { tLow and high perceived fall risks were scores of } \leq 22 \text { and } \geq 23 \text { on falls efficacy scale international. } \\
\text { łValues for low and high perceived fall risk were scores of } \leq 19 \text { and } \geq 20 \text { on falls efficacy scale international. } \\
\text { §Quadriceps strength values adjusted for sex. }\end{array}$} \\
\hline
\end{tabular}




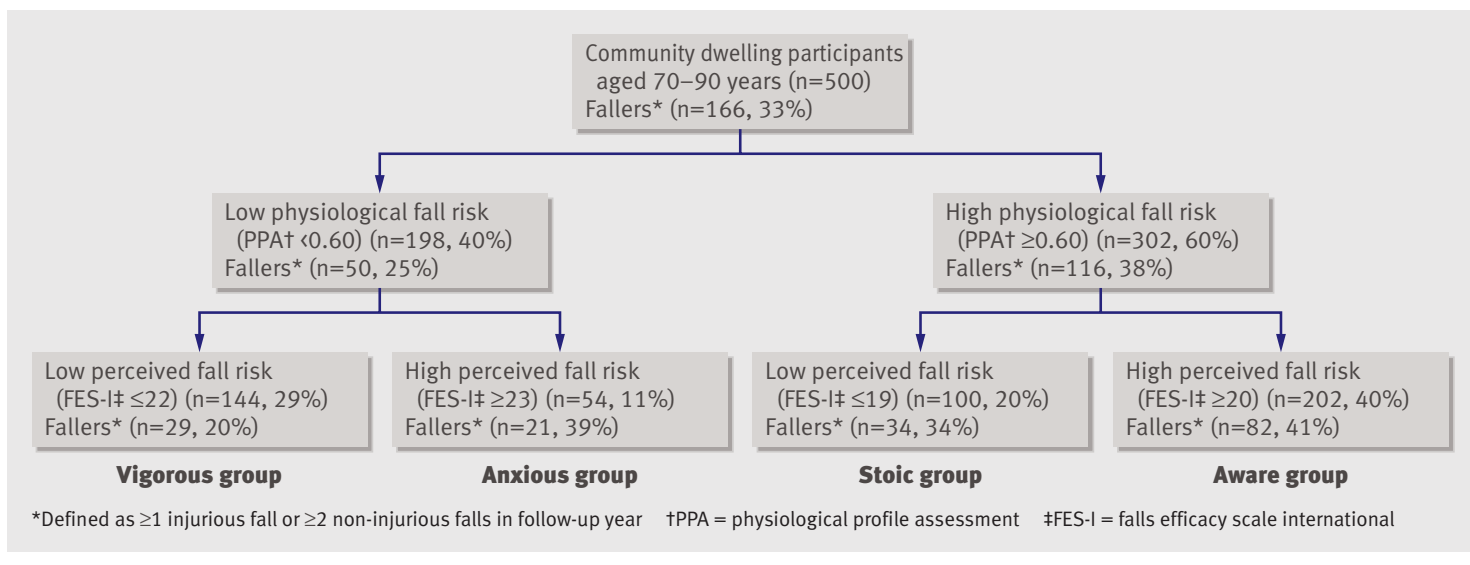

Fig 1 | Classification tree of 500 elderly people living in the community based on their physiological and perceived risks of falling

A classification and regression tree (CART) analysis was performed to establish a framework for categorising participants into four groups based on their physiological fall risk and perceived fall risk. CART analysis splits a continuous variable into two groups based on an exhaustive search of all possibilities. We also ran our data through a $\chi^{2}$ automatic interaction detection method to ensure there were no further subgroups. CART analysis is inherently non-parametric, and, therefore, no assumptions are made regarding the underlying distribution of values of the predictor variables.

Multivariate linear regression analyses were performed for all participants to explore the best set of independent and significant correlates with perceived fall risk. The physiological fall risk was entered first, followed by all variables showing a univariate relation with perceived fall risk at a significance level of 0.100 using the stepwise method. Additionally, differences were explored between the four identified groups from the CART analyses using analysis of variance. The data were analysed with SPSS.17 for Windows (SPSS, Chicago, USA).

\section{RESULTS}

The mean age of participants was 77.9 years (SD 4.6), and $270(54 \%)$ were women. In all, $149(30 \%)$ of participants reported one or more falls in the previous year, and $214(43 \%)$ reported one or more falls during the one year follow-up (six participants were lost during

Table 2 | Logistic regression output for the model relating odds of experiencing $\geq 1$ injurious fall or $\geq 2$ non-injurious falls among 494 elderly people living in the community based on their physiological and perceived risks of falling

\begin{tabular}{lcc} 
& Odds ratio $(95 \% \mathrm{Cl})$ of fall in 1 year & P value \\
$\begin{array}{l}\text { Physiological fall risk (physiological } \\
\text { profile assessment) }\end{array}$ & $1.23(1.01$ to 1.49$)$ & 0.039 \\
\hline $\begin{array}{l}\text { Perceived fall risk (falls efficacy scale } \\
\text { international) }\end{array}$ & $1.29(1.06$ to 1.57$)$ & 0.010 \\
\hline Constant & 0.49 & $<0.001$ \\
\hline
\end{tabular}

follow-up for falls). Table 1 presents all the outcome measures.

\section{Predicting injurious or multiple falls}

Univariate logistic regression analyses showed that the risk of experiencing an injurious or multiple fall $(\geq 1$ injurious fall or $\geq 2$ non-injurious falls) significantly increased with a higher physiological profile assessment score (odds ratio 1.31 (95\% confidence interval 1.06 to 1.61 ), $\mathrm{P}=0.011$ ) and with a higher falls efficacy scale international score (odds ratio 1.05 (1.02 to 1.08), $\mathrm{P}=0.001)$. Multivariate logistic regression analysis identified both risk factors as independent of each other and of similar importance $\left(\chi^{2}=13.32, \mathrm{df}=2\right.$, $\mathrm{P}=0.001$ ) (table 2).

\section{Classification tree}

The classification and regression tree analysis was used to split the sample into four groups (fig 1). The physiological profile assessment cut-point for low or high physiological fall risk identified in the model was 0.60 , and the falls efficacy scale international cutpoint for perceived fall risk was 23 in the group with a low physiological fall risk and 20 in the group with a high physiological fall risk. Thus the cut-point for perceived fall risk differed between those with a low or high physiological fall risk. We confirmed the validity of the cut-points by inspecting receiver operator curves and the Youden index. ${ }^{32}$ The cut-points for perceived fall risk are identical to those previously established for low and moderate falls efficacy when validated against three state variables-balance, previous falls, and depressive symptoms. ${ }^{33}$

Most people had an accurate perception of their fall risk: $144(29 \%)$ comprised a "vigorous" group who had both low physiological and perceived fall risks, and $202(40 \%)$ comprised an "aware" group who had both high physiological and perceived fall risks. About a third of our population, however, had disparities between their perceived and physiological fall risk: $54(11 \%)$ had low physiological fall risk but a high perceived risk and were classified as "anxious," and 100 
(20\%) had a high physiological risk but low perceived risk and were classified as "stoic."

\section{Explaining perceived fall risk}

Physiological fall risk (physiological profile assessment) and perceived fall risk (falls efficacy scale international) were independent risk factors of future injurious or multiple falls, but were also weakly but significantly related to each other $(r=0.19, \mathrm{P}<0.001)$ as shown in fig 2 . Multiple regression analysis revealed that, in addition to physiological fall risk, depressive symptoms (geriatric depression scale score) and quadriceps strength independently and significantly contributed to explaining perceived fall risk $\left(F_{3,497}=25.13, \mathrm{P}<0.001\right)$.

\section{Differences between groups}

Further exploration of significant differences between the four groups from the classification and regression tree analysis (table 1), showed that the people who rated their fall risk inappropriately high ("anxious") were more likely to be female, showed higher levels of self rated disability, had a lower quality of life, had more symptoms of depression, showed higher levels of neuroticism, scored poorly on executive functioning, and performed badly on the coordinated stability test compared with the group with an accurate perception of their low fall risk ("vigorous"). Interestingly, levels of planned exercise were the same for both groups.

People who rated their fall risk inappropriately low ("stoic") were younger, took fewer medications in total and fewer psychotropic medications, had lower levels of self rated disability, had a better reported quality of life, did more planned exercise, had fewer symptoms of depression, showed lower levels of neuroticism, were stronger, and performed better on the coordinated stability test compared with the group with an accurate perception of their high fall risk ("aware"). The stoics also experienced fewer falls in the previous year. The longitudinal design of our study allowed us to further explore the effect of injurious or multiple falls on perceived fall risk in the stoic group. Only six of the 34 stoics who fell during the follow-up year increased their concern about fall risk after an injurious or multiple fall, while the remainder stayed unconcerned about falls.

\section{DISCUSSION}

The finding that both physiological fall risk (measured by the physiological profile assessment) and perceived fall risk (measured by the falls efficacy scale international) contributed to the participants' future fall risk allowed us to explore the prevalence of irrational fear of falling. Most people had a congruent physiological and perceived risk, with the "vigorous" group being at low risk and the "aware" group at high risk. However, about a third had disparities between their physiological and perceived fall risk and were categorised as "anxious" or "stoic." Each group had specific medical, physiological, and neuropsychological profiles, which help in our understanding as to why

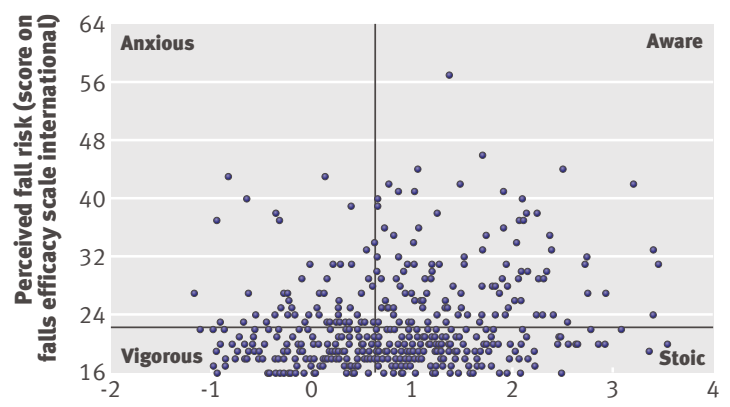

Physiological fall risk (score on physiological profile assessment)

Fig 2 | Physiological fall risk of 500 elderly people living in the community plotted against their perceived fall risk, and categorisation of people based on these values ("anxious," "aware," "vigorous," and "stoic")

elderly people have divergent perceived and physiological fall risks and the effects of such disparities on the risk of injurious or multiple falls.

\section{Comparison with other studies}

About $10 \%$ of the study population showed excessive levels of perceived fall risk and were classified as anxious. Despite their low physiological fall risk, almost $40 \%$ of the anxious group experienced multiple or injurious falls during the one year follow-up. In keeping with previous studies, we anticipated that self imposed restriction on levels of physical activity would contribute to overall risk in this group. ${ }^{513}$ However, there was no indication of lower levels of activity, so other reasons need to be explored as to why "anxious" participants fell more than "vigorous" participants during follow-up.

It is possible that the anxious group had a residual physiological fall risk not encompassed by the physiological profile assessment. Thus, although the group's low physiological profile assessment score indicated that the integrity of individual sensorimotor components was adequate, their relatively poor performance on the coordinated stability test suggests that the integration of each of these physiological systems in the maintenance of dynamic balance control was impaired. ${ }^{22}$ However, the disparity between physiological and perceived fall risk in the anxious group seemed to be strongly related to psychological factors. The group's psychological profile indicated a higher prevalence of irrational fears (higher levels of neuroticism), possibly leading them to interpret small balance impairments as major deteriorations in balance control. The poor performance on the coordinated stability test could be caused by fear induced stiffening. ${ }^{2}$ Additionally, the anxious group showed higher levels of depressive symptoms and decreased executive functioning, both of which are known risk factors for falls. ${ }^{242634}$ The underlying mechanisms to explain how depression could increase fall risk have been mainly attributed to reduced levels of physical activity and use of antidepressant medication, ${ }^{1324}$ but are still poorly understood and cannot be confirmed with our 


\section{WHAT IS ALREADY KNOWN ON THIS TOPIC}

Fear of falling is common in elderly people and is associated with poor balance, anxiety, depression, and falls

\section{WHAT THIS STUDY ADDS}

Almost a third of this sample of elderly people either underestimated or overestimated their risk of falls. Such

disparities between perceived and physiological fall risk were primarily associated with psychological measures and strongly influenced the probability of falling

The study implications are that measures of both physiological and perceived fall risk should be included in fall risk assessments so as to tailor interventions for preventing falls in elderly people

data. Impaired executive function may lead to falls, especially during dual tasking conditions, ${ }^{35}$ through subtle failures of inhibition of motor responses and visual attention. ${ }^{36}$

Twenty per cent of the study population showed an unduly low perceived fall risk and were classified as stoics. This aspect of fear of falling has been underinvestigated in studies of risk factors for falls. About one in three stoics fell in the follow-up year-a rate intermediate between those of the vigorous group and the aware group. We initially hypothesised that an inaccurately low perception of fall risk would lead to a higher rate of injurious or multiple falls through risk taking behaviour or poor insight. However, the psychological profile of stoics did not indicate excessive risk taking behaviour but rather a positive attitude to life, emotional stability, and low reactivity to stress.

Furthermore, the low perception of fall risk in the stoics seemed to be protective towards future falls compared with the aware group. This could be for three reasons. Firstly, the stoics seemed to maintain a more active lifestyle than the aware group, including more planned exercise with resultant higher muscle strength. Exercise is an effective strategy for preventing falls in elderly people ${ }^{37}$ and could therefore explain the lower fall rate in the stoic group. Secondly, the stoics used less psychotropic medication, which has consistently been shown to be a risk factor of falls. ${ }^{38}$ Thirdly, it is possible that the stoics had a low perceived fall risk because they had not experienced many previous falls, and therefore had less reason to consider they might fall in the future. Studies have suggested that the degree of fear of falling is associated with the number and seriousness of the falls experienced. ${ }^{11}$ This last hypothesis, however, was not supported by an additional analysis of our data, which showed that the stoics did not alter their perception of fall risk even if they experienced falls during the follow-up year. Therefore, it seems that the lower fall rate in people with unduly low perceived fall risk, as seen in the stoics, is probably mediated through a positive outlook on life and maintained physical activity and community participation. $^{39}$

\section{Clinical and future research implications}

Overall, it seems that high levels of perceived fall risk may lead to future falls, independent of physiological risk, and that the disparity between physiological and perceived fall risk contributes to fall risk mainly through psychological pathways. This indicates that measures of both physiological and perceived fall risk should be included in fall risk assessments. The inclusion of psychological and cognitive factors should improve the accuracy of prediction of falls. Categorisation of elderly people by the disparity between physiological and perceived fall risk may also assist in designing tailored interventions for preventing falls, including exercise and cognitive behavioural therapy. Exercise is recommended in recent, evidence based guidelines as one of the most effective falls prevention strategies. ${ }^{39}$ Cognitive behavioural therapy has been shown to reduce fear of falling ${ }^{40-42}$ and recurrent falls, ${ }^{42}$ especially in combination with exercise. ${ }^{14}$ People equivalent to our anxious group should be guided towards cognitive behavioural therapy with the aim of improving self efficacy and sense of control over falling, ${ }^{41}$ reducing symptoms of depression, ${ }^{43}$ and promoting an active and healthy lifestyle. ${ }^{42}$ Stoics should be motivated to participate in exercise programmes specifically designed to reduce fall risk, comprising high intensity balance training, ${ }^{37}$ in addition to their own exercise regimen. For the aware, a combination of both exercise and cognitive behavioural therapy is likely to be most effective. ${ }^{40}$ Given our finding that risk taking behaviour might not commonly exist, the reduction of fear of falling is not likely to be harmful or increase the risk of falls by making elderly people overly confident. Other evidence based prevention strategies should also be considered as appropriate.

\section{Limitations of study}

Our exploratory study was carefully designed towards the research questions in order to minimise limitations. However, two important limits exist. Firstly, although the physiological profile assessment has been shown to be a valid and reliable measure of falls risk, it is no more than an estimate and undoubtedly has shortcomings such as measurement error. Secondly, all data used to develop the psychological profiles of the participants were self reported. It is known that this may result in shared-method variance (strong associations between variables because of similar methods of measurement) and social desirability biases by denying difficulties in performance. Our sample largely consists of healthy, community dwelling, elderly adults and should be generalisable towards other community populations considering it had similar demographic, medical, and falls characteristics to those of other studies. ${ }^{251617}$ Although dichotomising the physiological profile assessment and the falls efficacy scale international provided a parsimonious way of assessing disparities between perceived and physiological fall risk, the cut-points we derived for these measures should be considered estimates only, as it can be seen from fig 2 that the cutpoints did not identify four distinct groups. Further 
studies are therefore necessary to confirm the cutpoints in external samples, and to investigate whether the same disparity categorisation can also be found in elderly people at increased risk of falls, including those with cognitive impairment and Parkinson's disease.

\section{Conclusion}

The study findings show that high levels of perceived fall risk are likely to result in future falls, independent of physiological risk, and the disparity between physiological and perceived fall risk contributes to risk mainly through psychological pathways. Measures of both physiological and perceived fall risk should be included in fall risk assessments and the proposed disparity categorisation may assist in designing tailored interventions for preventing falls in elderly people.

Contributors: KD and SRL drafted the manuscript. SRL, JCTC, and KD helped write the grant application for this project. All authors contributed to the manuscript's critical review and approved the final version. KD is guarantor for the study and had full access to all of the study data and takes responsibility for their integrity and the accuracy of the data analysis.

Funding: This research was conducted as part of a study on

"understanding fear of falling and risk-taking in older people," which was funded by the Australian National Health and Medical Research Council (grant No 400941). The participants in this study were drawn from the Memory and Ageing Study of the Brain and Ageing Program, School of Psychiatry, University of New South Wales, funded by a National Health and Medical Research Council grant (No 350833).

Competing interests: The physiological profile assessment (NeuRA FallScreen) is commercially available through the Neuroscience Research Australia.

Ethical approval: The University of New South Wales Human Research Ethics Committee approved the study protocol HREC 04229

Data sharing: The authors are willing to share data on request, providing a collaborative research proposal can be presented.

1 Lord SR. Predictors of nursing home placement and mortality of residents in intermediate care. Age Ageing 1994:23:499-504.

2 Maki BE, Holliday PJ, Topper AK. Fear of falling and postural performance in the elderly. J Gerontol 1991;46:123-31.

3 Maki BE. Gait changes in older adults: predictors of falls or indicators of fear? J Am Geriatr Soc 1997;45:313-20.

4 Cumming RG, Salkeld G, Thomas M, Szonyi G. Prospective study of the impact of fear of falling on activities of daily living, SF-36 scores, and nursing home admission. J Gerontol A Biol Sci Med SCi 2000;55:299-305.

5 Delbaere K, Crombez G, Vanderstraeten G, Willems T, Cambier D. Fear-related avoidance of activities, falls and physical frailty. A prospective community-based cohort study. Age Ageing 2004;33:368-73.

6 Friedman SM, Munoz B, West SK, Rubin GS, Fried LP. Falls and fear of falling: which comes first? A longitudinal prediction model suggests strategies for primary and secondary prevention. J Am Geriatr SoC 2002; 50:1329-35.

7 Bhala RP, O’Donnell J, Thoppil E. Ptophobia: phobic fear of falling and its clinical management. Phys Ther 1982;62:187-90.

8 Yardley L, Smith $\mathrm{H}$. A prospective study of the relationship between feared consequences of falling and avoidance of activity in community-living older people. Gerontologist 2002;42:17-23.

9 Arfken CL, Lach HW, Birge SJ, Miller JP. The prevalence and correlates of fear of falling in elderly persons living in the community. $\mathrm{Am}$ ) Public Health 1994:84:565-70.

10 Li F, Fisher KJ, Harmer P, McAuley E, Wilson NL. Fear of falling in elderly persons: association with falls, functional ability, and quality of life. J Gerontol B Psychol Sci Soc Sci 2003;58:283-90.

11 Howland J, Peterson EW, Levin WC, Fried L, Pordon D, Bak S. Fear of falling among the community-dwelling elderly. J Aging Health 1993;5:229-43.

12 Lawrence RH, Tennstedt SL, Kasten LE, Shih J, Howland J, Jette AM. Intensity and correlates of fear of falling and hurting oneself in the next year-baseline findings from a Roybal center fear of falling intervention. J Aging Health 1998;10:267-86.
13 Van Haastregt JC, Zijlstra GA, van Rossum E, van Eijk JT, Kempen GI. Feelings of anxiety and symptoms of depression in community-living older persons who avoid activity for fear of falling. Am J Geriatr Psychiatry 2008;16:186-93.

14 Zijlstra GAR, van Haastregt JCM, van Rossum E, van Eijk JTM, Yardley L, Kempen G. Interventions to reduce fear of falling in community-living older people: a systematic review. J Am Geriatr Soc 2007;55:603-15.

15 Sachdev P, Brodaty H, Reppermund S, Kochan N, Trollor J, Draper B, et al. The Sydney Memory and Ageing Study (MAS): methodology and baseline medical and neuropsychiatric characteristics of an elderly epidemiological non-demented cohort of Australians aged 70-90 years. Int Psychogeriatr 2010;19:1-17 (epub, doi:10.1017/S1041610210001067).

16 Lord SR, Menz HB, Tiedemann A. A physiological profile approach to falls risk assessment and prevention. Phys Ther 2003;83:237-52.

17 Tinetti ME, Powell L. Fear of falling and low self-efficacy: a cause of dependence in elderly persons. J Gerontol 1993;48:35-8.

18 Concato J, Feinstein AR, Holford TR. The risk of determining risk with multivariable models. Ann Intern Med 1993;118:201-10.

19 World Health Organization. WHO disability assessment schedule II (WHODAS II). 2001. www.who.int/icidh/whodas/index.html.

20 Richardson J, Peacock S, Stuart, lezzi A, Day N, Hawthorne G. The assessment of quality of life (AQoL) II instrument overview and creation of the utility scoring algorithm. 2007. www.buseco.monash edu.au/centres/che/pubs/rp17.pdf.

21 Delbaere K, Hauer K, Lord SR. Evaluation of the incidental and planned exercise questionnaire (IPEQ) for older people. Br J Sports Med 2010; published online 22 April.

22 Lord SR, Ward JA, Williams P. Exercise effect on dynamic stability in older women: a randomized controlled trial. Arch Phys Med Rehabil 1996;77:232-6.

23 Yardley L, Beyer N, Hauer K, Kempen G, Piot-Ziegler C, Todd C. Development and initial validation of the falls efficacy scaleinternational (FES-I). Age Ageing 2005;34:614-9.

24 Tinetti ME, Speechley M, Ginter SF. Risk factors for falls among elderly persons living in the community. $N$ Engl J Med 1988;319:1701-7.

25 Mann R, Birks Y, Hall J, Torgerson D, Watt I. Exploring the relationship between fear of falling and neuroticism: a cross-sectional study in community-dwelling women over 70. Age Ageing 2006;35:143-7.

26 Holtzer R, Friedman R, Lipton RB, Katz M, Xue X, Verghese J. The relationship between specific cognitive functions and falls in aging. Neuropsychology 2007;21:540-8.

27 Sheikh J, Yesavage J. Geriatric depression scale (GDS): recent evidence and development of a shorter version. In: Brink TL, ed. Clinical gerontology: a guide to assessment and intervention. Haworth Press,1986:165-73.

28 Goldberg D, Bridges K, Duncan-Jones P, Grayson D. Detecting anxiety and depression in general medical settings. BMJ 1988;297:897-9.

29 Costa PT Jr, McCrae RR. Revised NEO personality (NEO-PI-R) and NEO five factor inventory (NEO FFI) professional journal manual. Psychological Assessment Resources, 1992.

30 Reitan RM, Wolfson D. The Halstead-Reitan neuropsychological test battery. Neuropsychology Press, 1985.

31 Lamb SE, Jorstad-Stein EC, Hauer K, Becker C. Development of a common outcome data set for fall injury prevention trials: the Prevention of Falls Network Europe consensus. J Am Geriatr Soc 2005;53:1618-22

32 Perkins NJ, Schisterman EF. The inconsistency of "optimal" cutpoints obtained using two criteria based on the receiver operating characteristic curve. Am J Epidemiol 2006;163:670-5.

33 Delbaere K, Close J, Mikolaizak A, Sachdev P, Brodaty H, Lord S. The falls efficacy scale international (FES-I). A comprehensive longitudinal validation study. Age Ageing 2010;39:210-6

34 Anstey KJ, Wood J, Kerr G, Caldwell H, Lord SR. Different cognitive profiles for single compared with recurrent fallers without dementia. Neuropsychology 2009;23:500-8.

35 Lundin-Olsson L, Nyberg L, Gustafson Y. "Stops walking when talking" as a predictor of falls in elderly people. Lancet 1997;349:617.

36 Salthouse TA. The processing-speed theory of adult age differences in cognition. Psychol Rev 1996;103:403-28.

37 Sherrington C, Whitney JC, Lord SR, Herbert RD, Cumming RG, Close ICT. Effective exercise for the prevention of falls: a systematic review and meta-analysis. I Am Geriatr Soc 2008;56:2234-43.

38 Campbell AJ, Robertson MC, Gardner MM, Norton RN, Buchner DM. Psychotropic medication withdrawal and a home based exercise programme to prevent falls: results of a randomised controlled trial. I Am Geriatr Soc 1999;47:850-3.

39 Gillespie L, Robertson M, Gillespie W, Lamb S, Gates S, Cumming R, et al. Interventions for preventing falls in older people living in the community. Cochrane Database Syst Rev 2009;2:CD007146. 
40 Brouwer BJ, Walker C, Rydahl SJ, Culham EG. Reducing fear of falling in seniors through education and activity programs: a randomized trial. J Am Geriatr Soc 2003;51:829-34.

41 Tennstedt S, Howland J, Lachman M, Peterson E, Kasten L, Jette A. A randomized, controlled trial of a group intervention to reduce fear of falling and associated activity restriction in older adults. J Gerontol B Psychol Sci Soc Sci 1998;53:384-92.

42 Zijlstra GAR, Van Haastregt JCM, Ambergen T, Van Rossum E, Van Eijk JTM, Tennstedt SL, et al. Effects of a multicomponent cognitive behavioral group intervention on fear of falling and activity avoidance in community-dwelling older adults: results of a randomized controlled trial. J Am Geriatr Soc 2009;57:2020-8.

43 Niederehe G. Psychosocial therapies with depressed older adults. In Schneider LS, Lebowitz BD, Friedhoff AJ, eds. Diagnosis and treatment of depression in late life. American Psychiatric Press, 1994:293-315.

Accepted: 8 June 2010 